\title{
Variability of modeled runoff over China and its links to climate change
}

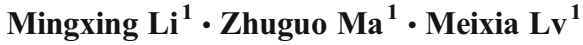

Received: 27 September 2015 / Accepted: 23 December 2015 /Published online: 18 January 2016

C The Author(s) 2016. This article is published with open access at Springerlink.com

\begin{abstract}
Runoff is a key component of the water cycle over land, with direct impact on regional ecosystems and water resources. This study investigates historical runoff variability and change over China in 1951-2008 using the Community Land Model and in situ observations of atmospheric forcing fields. Model simulations are first evaluated against in situ observations of streamflow for four major rivers, as well as soil moisture and water table depths, before further analysis is conducted. Then, quantile regression is used to analyze runoff variability and its relation to precipitation and temperature. The spatial pattern of monthly climatological runoff over China is characterized by maxima in the humid south and a gradual decrease toward the arid northwest. Runoff increases in the humid south, slightly decreases in the transition zone, and shows nonsignificant trends in the arid northwest. The footprint of decadal variability can be seen from 1951 to 2008. The annual precipitation advances the spatiotemporal variability of runoff despite locally distinct runoff-precipitation responses. The runoff-temperature relationship shows complex spatiotemporal characteristics that depend on the feedback from precipitation.
\end{abstract}

\section{Introduction}

Runoff variability and change have attracted attention because of their impacts on water resources management and use and the consequent redistribution of economic and environmental benefits (e.g., Oki and Kanae 2006). Such concerns stem from observations that show significant changes in the Earth's hydrological cycle in the context of climate change and the

This article is part of a Special Issue on "Regional Earth System Modeling" edited by Zong-Liang Yang and Congbin Fu.

Electronic supplementary material The online version of this article (doi:10.1007/s10584-015-1593-x) contains supplementary material, which is available to authorized users.

Mingxing Li

limx@tea.ac.cn

1 RCE-TEA, Institute of Atmospheric Physics, Chinese Academy of Sciences, Beijing 100029, China

2 Huayanli 40\#, Chaoyang District, Beijing 100029, People’s Republic China 
increased risk for extreme runoff and flooding (Wentz et al. 2007). In the case of China, one of the most water-scarce countries in the world, water shortage has long been a serious problem. To address this problem, the government has invested huge resources in water and ecohydraulic infrastructure. However, such efforts are subject to uncertainty because of the considerable changes in the runoff regime.

The Fifth Assessment Report of the Inter-Governmental Panel on Climate Change (IPCC) argues that the global surface air temperature has increased by $0.72-0.85{ }^{\circ} \mathrm{C}$ since the beginning of industrialization, with a particularly steep increase in recent decades (IPCC 2013). Presumably, because of global warming, the annual maximum daily precipitation has increased $8.5 \%$ over the last 110 years, resulting in runoff variability (Asadieh and Krakauer 2015). In China, a large body of work has been amassed for various watersheds, addressing the runoff variability during recent decades. For instance, increasing annual mean runoff was observed in the East River and the Yangtze River basins, South China (Zhang et al. 2015; Zhang et al. 2006). In Northwest China, runoff also increased during the past 50 years, with a step-like change in precipitation at approximately 1986 (Chen et al. 2006). In contrast, in the Yellow River basin, runoff has been decreasing in recent decades (Zhang et al. 2009). The combination of decreased precipitation and increased human activities is considered to decrease runoff, as in the Northeast from 1965 to 2005 (Zhang et al. 2012). However, it is yet unclear whether these changes have any coherent countrywide spatial patterns and what drives these changes.

Regarding the link of runoff variability to climate change, water balance modeling suggests that the water-year precipitation accounts for almost all of the runoff variations. Furthermore, the temperature effect on runoff is small even during the period of significantly increased temperature (McCabe and Wolock 2011). Observations have shown that seasonal variations in runoff and summer monsoon precipitation, as well as pronounced warming and drying (runoff), are strongly correlated on decadal timescales (Xue et al. 2005). For example, in the Yangtze River basin, the correlation coefficient between runoff and precipitation is up to 0.89 (Chen et al. 2014). However, land use changes (i.e., forestation), glacial melting, and human activities make the relationship much more complex, especially in recent decades. For instance, Bi et al. (2009) reported that forestation had reduced the annual streamflow in a watershed in the Loess Plateau by $49.63 \%$ from 1954 to 2008. Therefore, at a countrywide scale, the pattern of interaction between runoff variability and climate change remains an open question.

At present, global climate projections suggest that the global water cycle will be strengthened due to the increased moisture-holding capacity of the atmosphere and the surface energy supply (Wu et al. 2013; Wu et al. 2010). Land runoff plays a very important role in the global hydrological cycle. Regionally, runoff is a vital component of the water cycle of a watershed, and it is critical to ecosystem services and water resource management, particularly in the arid and semiarid areas of China. Thus, this study examines countrywide patterns of runoff variability, along with extremes over critical regions, and the links to climatic covariates by quantile regression. In section 2 , we discuss the model development and data. In section 3, we discuss the evaluation of the modeling, the spatial patterns of runoff variability, the variability over critical regions, and the relations of runoff to precipitation and temperature. The conclusions are summarized in section 4 . 


\section{Model and data}

\subsection{Experimental design}

\subsubsection{Model description}

The Community Land Model (CLM) is the land model for the Community Earth System Model. CLM represents several aspects of the land surface, including surface heterogeneity, and it consists of components or submodels related to the hydrologic cycle, land biogeophysics, ecosystem dynamics, biogeochemistry, and human dimensions.

From version 3.5 onward, CLM contains water-related parameterization schemes [for instance, a simple TOPMODEL-based runoff scheme (SIMTOP) and a simple groundwater scheme (SIMGM)] along with improvements in soil water availability and resistance terms to reduce the overestimated soil evaporation (Niu et al. 2005; Oleson et al. 2008; Yang and Niu 2003). CLM version 3.5 (CLM 3.5) offers significant improvements in estimating the subcomponents of the land water cycle (Oleson et al. 2008). Nevertheless, CLM 3.5 produces higher soil moisture and lower variability than observations in the rooting zone. To reduce these biases, $\mathrm{Li}$ and $\mathrm{Ma}$ (2015) introduced a factor to describe soil porosity, increase the recharging water from the soil column to the aquifer, and reduce the flux in the opposite direction, as achieved by Lawrence et al. (2011) and Niu et al. (2011).

Newer CLM versions (4.0 and 4.5) offer improved solutions related to soil moisture and biogeochemical processes. However, the soil moisture variability remains low compared with observations (Lawrence et al. 2011). Based on our assessment of the applicability of CLM 3.5 across China and the observation-based datasets (Li and Ma 2010; Li et al. 2011), we opted for CLM 3.5 to regenerate the long-term runoff variability. For a detailed description of CLM 3.5, the readers are referred to Oleson et al. (2004) and the references therein.

\subsubsection{Atmospheric forcing and land data}

We constructed an observation-based atmospheric forcing dataset involving four state variables (air temperature, pressure, wind speed, and specific humidity) and two flux variables (precipitation and radiation). Historical measurements of precipitation, air temperature, pressure, and wind speed were taken from the China Meteorological Administration (CMA), and the specific humidity was calculated from dry- and wetbulb temperature observations. We adopted the radiation data of Sheffield et al. (2006) by bilinear interpolation to compensate for the scarcity of radiative observations. Using Kriging for spatial and curve fitting for temporal interpolations, the resulting atmospheric forcing dataset has $0.5^{\circ} \times 0.5^{\circ}$ horizontal resolution, a 3-h temporal interval, and a 58year time span (1951-2008). As for the details of establishing the forcing field and the evaluation of the modeling of the land water cycle, the readers are referred to $\mathrm{Li}$ and $\mathrm{Ma}$ (2010). The land data used in this study consist of topography, soil attributes, plant functional types, and physiological parameters of vegetation. We retained the default data in CLM 3.5, which were mostly taken from the Moderate Resolution Imaging Spectroradiometer (MODIS) land surface mapping (Lawrence and Chase 2007). 


\subsubsection{Simulation configuration}

The simulation of runoff was conducted in the off-line mode over China and was driven by the aforementioned observation-based forcing with the activated river-routing model [RTM (Branstetter and Erickson 2003)] and the dynamic global vegetation model. To eliminate the initialization effects and examine the long-term integration ability, considering variable time scales of land water cycles (soil water and groundwater), we ran CLM continuously for 400 years by cycling the 1951-2000 forcing and then running from 1951 to 2008. The last 58 -year run was used to understand the spatiotemporal nature of runoff across China.

\subsection{Observational data}

Routine in situ observations from CMA [the China Meteorological Data Sharing Service System (CMDSSS, http://www.cma.gov.cn/2011qxfw/2011qsjgx)] were used for establishing the aforementioned forcing fields. In addition, gridded monthly precipitation and temperature by CMA over China were applied to explore the relationship between runoff and climate change. Compared with the forcing fields, the same in situ observations were largely used, but they were gridded by independent interpolating algorithms. Merged satellite-ground observations of monthly precipitation for 1979-2008 from the Global Precipitation Climatology Project (GPCP) were also used to cross-validate the CMA's dataset. The monthly terrestrial water storage (TWS) data from the Gravity Recovery and Climate Experiment (GRACE) were used to evaluate the groundwater simulation. The arithmetic averages of TWS were obtained from three datasets by the NASA's Jet Propulsion Laboratory (JPL), the University of Texas at Austin Center for Space Research (CSR), and the German Research Centre for Geosciences Potsdam (GFZ). Release-05 of the GRACE Level-2 data (spatial resolution of $1^{\circ}$ ) was used here, which has improved the accuracy over its precursor owing to new data processing algorithms (Landerer and Swenson 2012).

Monthly streamflow data were measured at the Chiling, Lijin, Datong, and Wuzhou sites and are used to evaluate the 1960-2000 runoff simulations over four river basins in China from north to south - the Liao River, the Yellow River, the Yangtze River, and the Xijiang River. The records from Dai et al. (2009) are referred to as natural streamflow that were taken from gauged streamflow data by estimating the human-caused upstream water loss.

\section{Results}

\subsection{Evaluation of runoff simulation}

Two aspects broadly affect the fidelity of a simulation: input quality and model adequacy. In this study, the former primarily originates from the atmospheric forcing fields. Li and Ma (2010) have shown that observation-based forcing has a clear advantage over the widely-used reanalysis data at the watershed scale. As for the latter, the main three components of the water cycle over land, i.e., soil moisture, runoff, and groundwater (water table depth), were evaluated. The modeled and observed soil moisture over China agreed well. For instance, the average correlation coefficient is up to 0.83 in Northeast China, where measurements are mostly available for summers during 1990-2000 (statistical details, see Li and Ma 2015). 
Regarding the runoff simulation, Fig. 1 compares simulations and observations for the four rivers over the period 1960-2000. The comparison shows considerable consistency between model streamflow (runoff transported by RTM coupled with CLM into the river channel) and measurements in terms of correlation coefficients and linear trends. For annual averages, the correlation coefficients for the Chiling, Lijin, Datong, and Wuzhou sites, near the mouths of the Liao, Yellow, Yangtze, and Xijiang Rivers, are 0.69, 0.79, 0.96, and 0.82, respectively, with a degree of freedom of 39 . Three of the four modeled linear trends are consistent with observations, except for the opposite trend at the Wuzhou site. A significant decrease is only observed at Lijin, and the model successfully captured it. The simulations also successfully captured the pronounced peaks and troughs, such as the high-flow runoffs in 1964 in the Liao River, 1964 in the Yellow River, and 1994 in the Xijiang River, as well as the low-flow runoffs of 1982 in the Liao River, and 1963 in the Xijiang River. From a decadal-scale perspective, the simulated runoff reasonably regenerated the increase-decrease transition from the 1980s to the 1990s in the Liao River, as well as the turning point from the 1980s' decrease to the 1990s' increase in the Xijiang River (not shown in the figure).
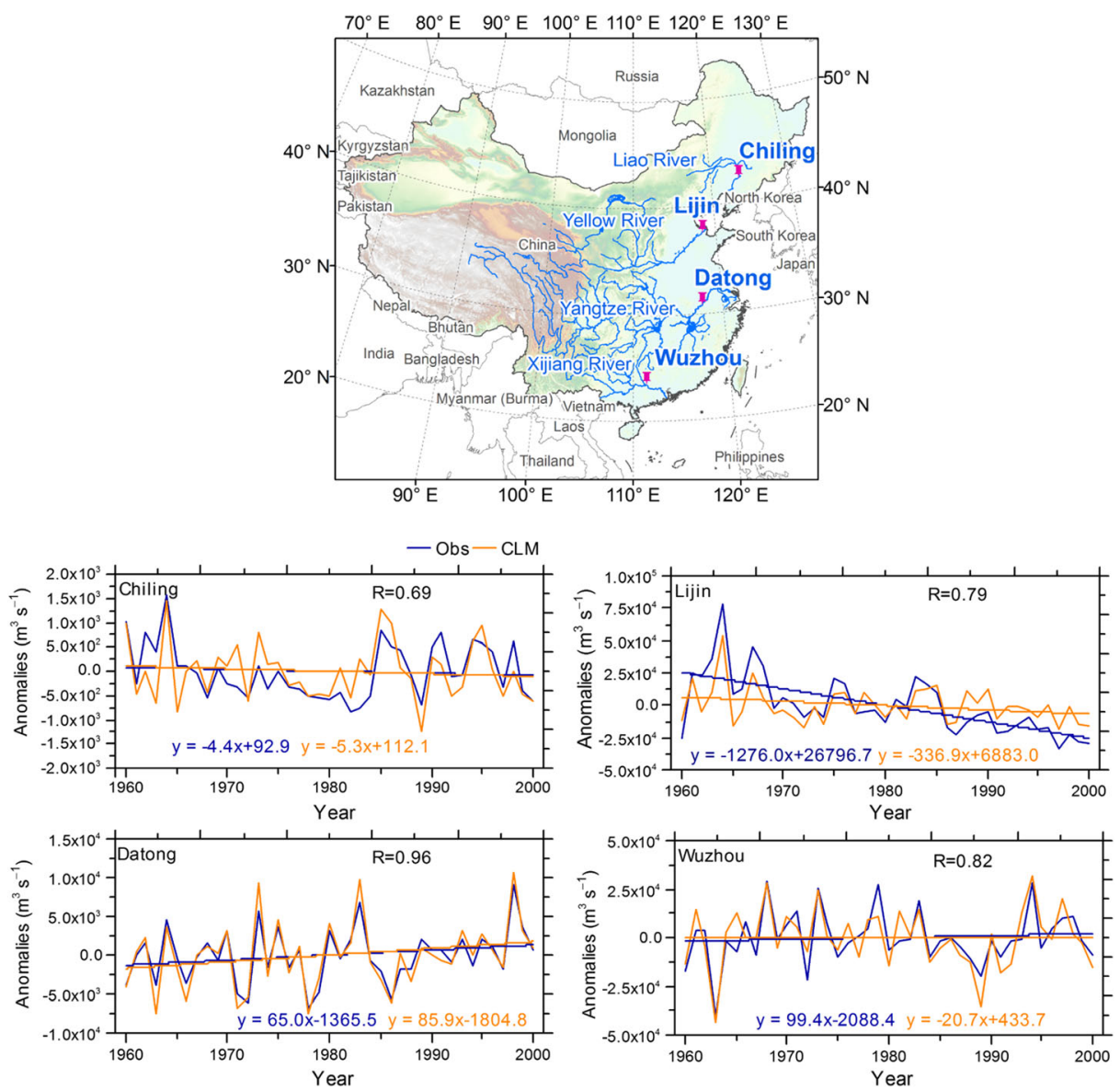

Fig. 1 Comparison of model and observed streamflow anomalies in 1960-2000, where R is the correlation coefficient and the dotted lines are linear regressions for the different sites 
Groundwater plays an important role in runoff generation over most areas. Because in situ observations are presently lacking, satellite-based TWS anomalies from GRACE are used instead. Area-averaged monthly water table depths from GRACE agree well with the model data for 2004-2008 over China (Supplementary Fig. S1), with a correlation coefficient of 0.87. The correlation coefficient between the time series without annual variations is 0.56 . The model annual variation mostly captures the observed behavior, except for one month prior to the measured peak.

By comparing the three major reservoirs of the land water cycle (soil water, runoff, and groundwater) to the corresponding observations, we validated the land water cycle simulations on various time scales. The results demonstrated that the land model (CLM version 3.5) with observation-based forcing largely captured the spatial patterns and long-term trends in the major land water cycles, especially of runoff, which supports the following analysis of runoff. Nevertheless, it is noteworthy that, between the model and observed variables, discrepancies appeared in varying regions and periods, for which no reasonable interpretation presently exists.

\subsection{Spatial runoff pattern}

The climatological patterns for 1951-2008 (Fig. 2) suggest that the averaged total runoff (surface and subsurface runoff) gradually decreased from southeast to northwest, as well as from humid to arid areas in China, with a maximum near $200 \mathrm{~mm}$ per month and a minimum near zero. Surface runoff is a significant contributor to total runoff in the humid south, whereas the amount of surface runoff decreases remarkably from southeast to northwest with the climate transition to aridness. Furthermore, subsurface runoff is the major contributor, especially in the humid climates. The analogous spatial structure is also observed in the patterns of the ratios of runoff to precipitation (Supplementary Fig. S2). Regarding the surface-subsurface runoff partitioning (Supplementary Fig. S3), from CLM 4.0 onward, CLM shifts the ratios of surface to subsurface runoff from $30: 70 \%$ to $55: 45 \%$ in light of sensitivity experiments by changing the solutions of the saturation excess terms and subsurface runoff (Lawrence et al. 2011). In this study, the default values are retained for these parameters because no gauge data are available for China to confirm this modification. We will address such issues in future studies.

Regarding the linear trends of runoff variations from 1951 to 2008 (Fig. 2, Supplementary Fig. S3), distinct characteristics were manifested as significant decreases over the wet-dry transition zone and significant increases over humid regions, with extremes of -0.3 and $1.0 \mathrm{~mm}$ per month, respectively. Over northwestern China, arid regions showed slightly increasing trends. The surface runoff contributed to the critical trends mainly over the mountains and plateaus, such as the Tian Shan Mountains, the rim of the Tibetan Plateau, and the Yuannan-Guizhou Plateau, where the melted glaciers added to the runoff. In addition, opposite trends in the surface and subsurface runoff appeared in the north of the Tian Shan Mountains, the Northeast Plain, and in the lower reaches of the Yangtze River (Supplementary Fig. S3).

The linear trends discussed above are calculated using ordinary least squares regression, and they show the rate of change in the mean of the runoff distribution as a function of time. Extreme changes, however, were identified as an important aspect of the runoff response to climate change and the variability due to global warming. Therefore, we calculated the slopes of the 0.1 and 0.9 quantiles that correspond to the 


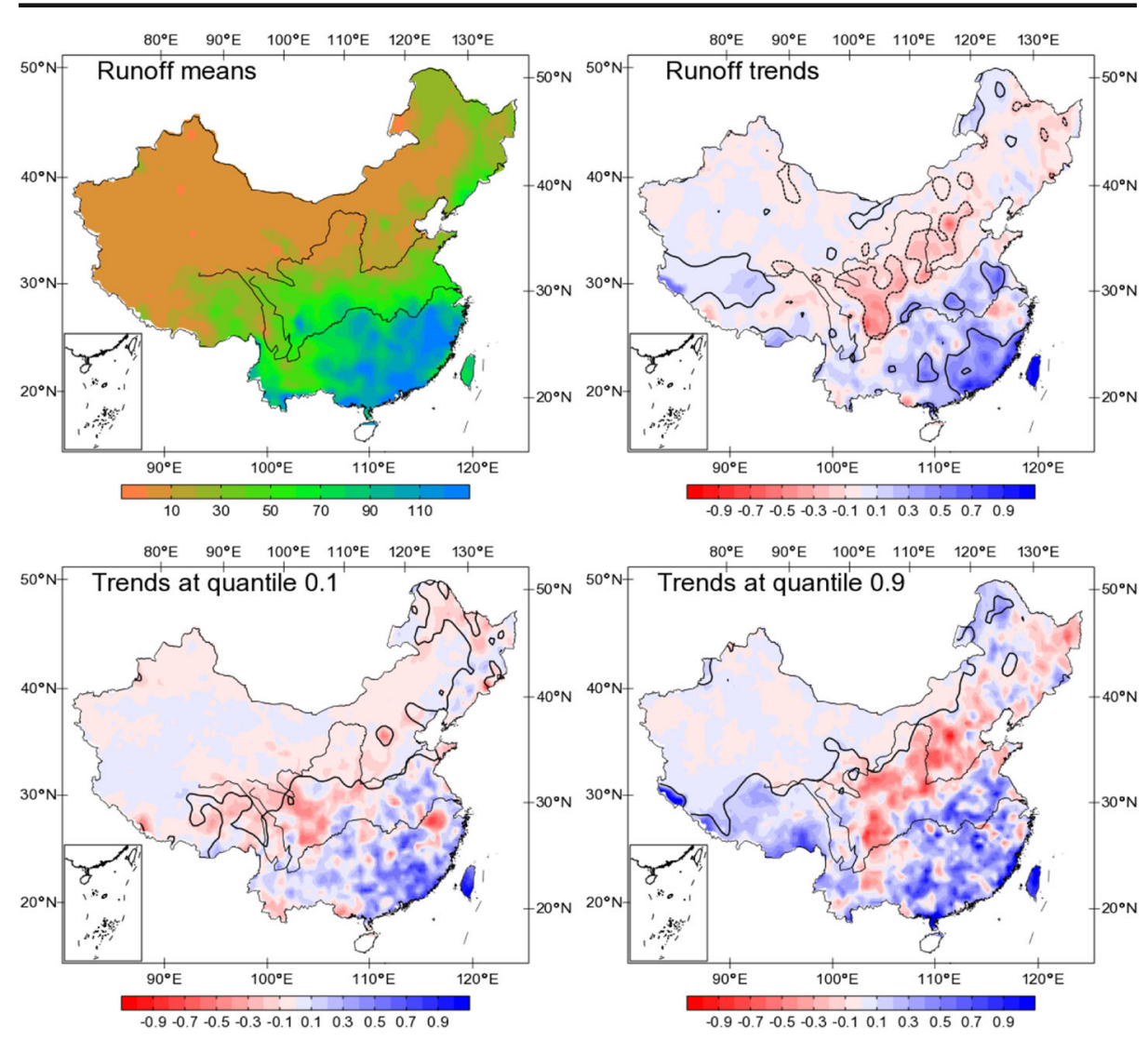

Fig. 2 Spatial patterns for the means of runoff $\left(\mathrm{mm} \mathrm{mo}^{-1}\right)$ and linear trends $\left(\mathrm{mm} \mathrm{mo}^{-1}\right)$, as well as the quantile trends $\left(\mathrm{mm} \mathrm{mo}^{-1}\right)$ for the 0.1 and 0.9 quantiles, over China for 1951-2008. The black lines denote significance at the 0.05 level

lower $10 \%$ (minima) and upper $90 \%$ (maxima) of the sorted runoff series for each grid cell to address the extreme changes in runoff in 1951-2008 (Fig. 2). The trends for the 0.1 and 0.9 quantiles show increasing runoff over humid southeastern China and largearea decreasing runoff over semiarid and semihumid regions. Nevertheless, discrepancies appeared mainly over parts of northeastern China, northwestern China, the Tibetan Plateau, and other areas. Over most of these regions, the upper quantile (extreme) trends are characterized by increases, whereas the lower quantile (extreme) trends show decreases or small increases. In addition, where trends were statistically significant at the 0.05 level, the upper quantile trends were generally much steeper than the lower quantile trends. The transition of quantile trends from 0.1 to 0.9 is provided in the Supplementary Materials (Supplementary Fig. S4). These differences indicate that the change in extreme runoff generally intensified from 1951 to 2008, associating directly with the increased extreme precipitation (Zhai et al. 2005). Spatially, the trend patterns for the frequency of days and amounts of extreme precipitation are in good agreement with the extreme runoff variations (Zhai et al. 2005). Moreover, the interdecadal oscillations, i.e., two abrupt changing points in 1978 and 1992, were associated with the weakening of the East Asian summer monsoon (Ding et al. 2008). 


\subsection{Temporal variability over critical regions}

For the spatial similarity of the runoff trends (surface, subsurface, and total runoff), we focus on the temporal variations where their trends are statistically significant (negative/positive trends responding to Region A/B, respectively, in Fig. 3a). Over the typical wet-dry climate transition zone (Region A), an averaged decreasing trend is observed for 1951-2008. Over the humid climate (Region B), an increasing trend is observed for the same period. The increasing trend is steeper than the decreasing one, with regression slopes of 0.35 and $-0.19 \mathrm{~mm}$ per month, respectively (Supplementary Fig. S5).

For each region, the regression lines for the $0.1,0.3,0.5,0.7$, and 0.9 quantile along with the quantile slopes and corresponding standard errors (Tab. S1) suggest that the highest quantile (0.9) shows the fastest increase in the positive trend region, and the lowest quantile (0.1) has the slowest increase. Moreover, in the negative trend region, the highest quantile shows the slowest decrease, whereas the lowest quantile shows the fastest decrease in 19512008. In other words, the amount of extreme runoff increased with an increase in runoff amount. Even in the case of decreased runoff amount, the upper quantile (0.9) decreased by
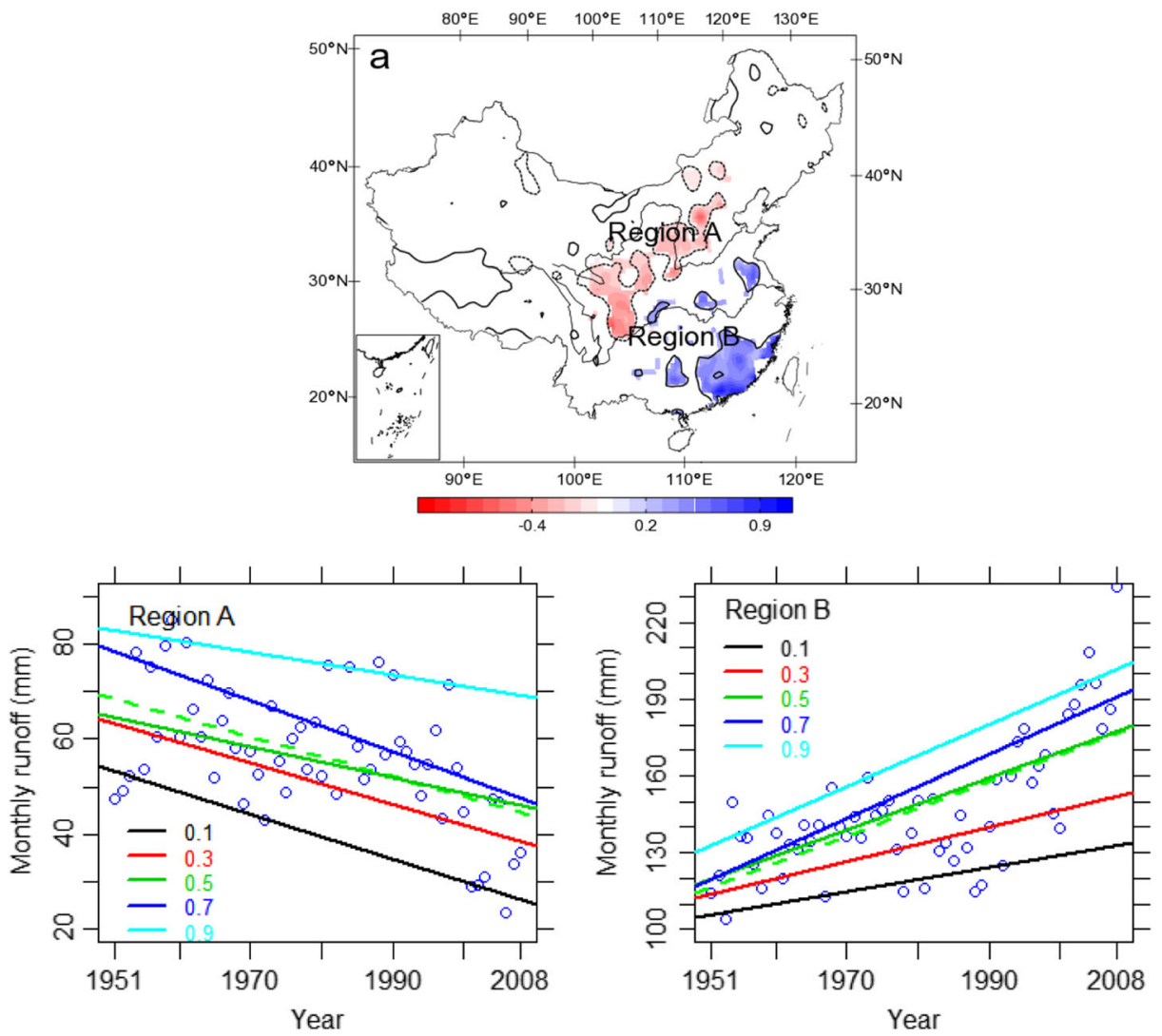

Fig. 3 Summer (JJA) monthly runoff as a function of time in two critical regions. Regression lines are for the quantiles $0.1,0.3,0.5,0.7$, and 0.9 . The dashed line represents the mean $(0.5)$ and is obtained from ordinary least squares regression 
$39 \%$ relative to the lower quantile (0.1) slope. Such variability in the extreme runoff agrees well with the extreme precipitation over East China (Lu et al. 2014; Zhai et al. 2005).

\subsection{Relation to precipitation and temperature}

Between summer runoff and precipitation, the correlations coefficients of 0.65 and 0.64 for Regions A and B, respectively, suggest that precipitation is critical to the runoff variations (Supplementary Fig. S6), whereas the correlation coefficients for temperature are more complex, i.e., -0.22 and 0.10 for Regions A and B for the summers of 1961-2008. Furthermore, for both Regions A and B (Fig. 4), the covariations between precipitation and runoff show consistently positive correlations in the quantiles from 0.1 to 0.9 , with slopes significantly different from zero (no trend) at the $95 \%$ confidence interval (Supplementary Fig. S7). This verifies the dominant control of precipitation on the summer runoff variations. As for the coupling between runoff and temperature, the two variables have identical signs at lower quantiles but opposite signs at the upper quantiles, switching at approximately the median quantile (Supplementary Fig. S7). Quantile regressions suggest that, with regional warming,
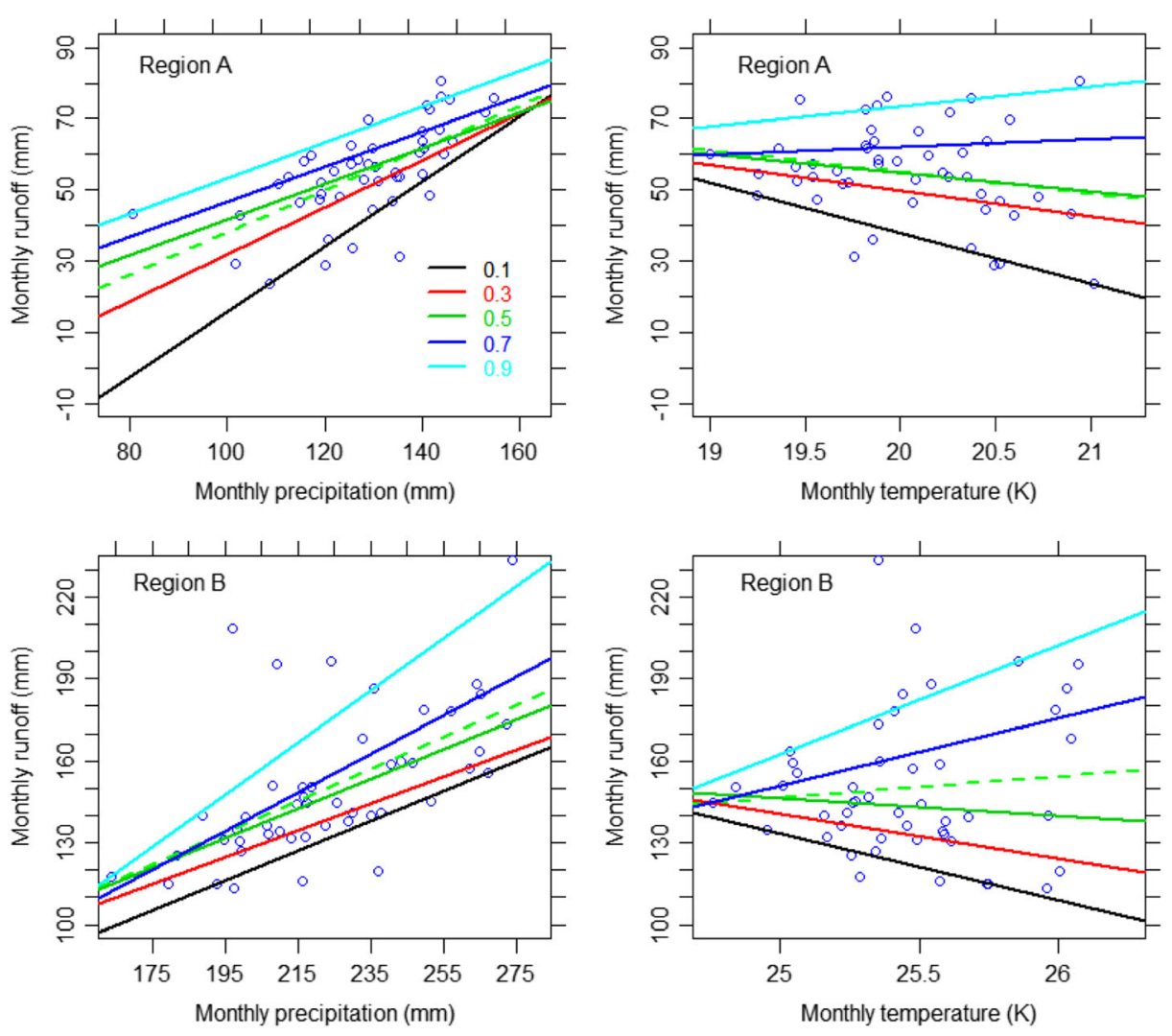

Fig. 4 Summer (JJA) monthly runoff as a function of monthly precipitation and temperature for two critical regions. Regression lines are at quantiles $0.1,0.3,0.5,0.7$, and 0.9 . The dashed line represents the mean $(0.5)$ and is obtained using ordinary least squares regression. The $95 \%$ confidence intervals of the slopes are shown in Supplementary Fig. S5 
the lower end of the runoff decreased but the upper end of the runoff increased. Accordingly, the runoff-temperature covariations can be affected by the variability in precipitation with rising temperature. Commonly, in the areas where the precipitation remains unchanged, the higher temperature causes an enhancement of the evapotranspiration, contributing to the decline in runoff. However, the precipitation change, accompanying that of cloud coverage, makes the nonlinear response of runoff to temperature more complex, especially when combined with the resulting changes in glacier, permafrost, wetland, lake, groundwater level, and vegetation cover (McCabe and Wolock 2011; Xu 2015).

The spatial patterns of the correlation between runoff and precipitation for the summers in 1961-2008 (Fig. 5) show that the correlation is positive countrywide, except for the nonsignificant negative relation in the dry-wet transition zone. The linking of temperature with runoff suggests a more mixed spatial structure, with significantly negative correlation over South China, North China, and most arid regions and positive correlation over most of the Tibetan Plateau, Sichuan Basin, and northern coastal areas. Such correlation changes reflect the evident seasonal and regional characteristics of the interactions between runoff and climate covariates. In contrast, the correlation pattern between the annual means of runoff and precipitation (Supplementary Fig. S8) is similar to the spatial structure of the precipitation climate. In
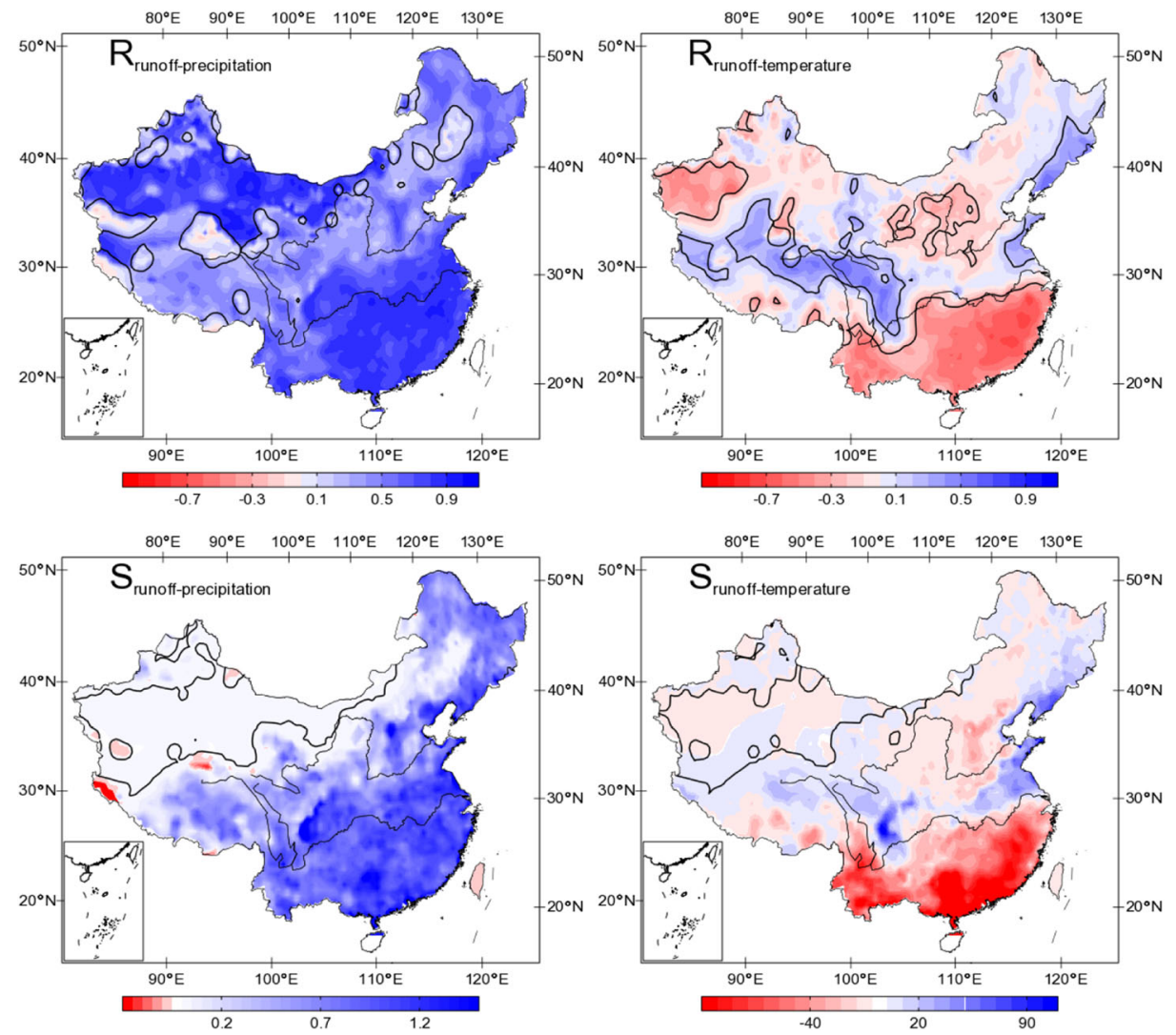

Fig. 5 Spatial patterns of the correlation coefficients (R) for runoff and precipitation, temperature, and response sensitivity (quantile slopes, S) at the 0.9 quantile for the summers (JJA) in 1961-2008. Black lines indicate significance at the 0.05 level 
particular, negative or weakly positive correlation dominates the arid regions. Regarding temperature, the spatial characteristics resemble that of runoff as a function of precipitation, with negative correlation over arid regions and positive over humid regions.

As an index reflecting the sensitivity of runoff to climatic covariates, the slope patterns of the regressions for quantiles 0.1 to 0.9 show weak spatial changes compared with magnitude. For example, the spatial structures of the lower and upper quantiles at 0.1 and 0.9 (Fig. 5, Supplementary Fig. S9) show that the summer runoff is most sensitive to the precipitation variations at the lower quantiles over areas where the absolute precipitation is relatively high, such as the Yangtze River basin and its south regions and parts of Northeast China. As the quantiles shift to the upper end (0.9), the runoff response to precipitation increases and extends northwards. For the link between runoff and temperature, the most sensitive coupling is mainly seen southward of the Yangtze River, with negative slopes up to $-75 \mathrm{~mm} \mathrm{~K}^{-1}$. At the 0.9 quantile, the strongly negative slopes remained over the regions south of the Yangtze River, with values exceeding $-100 \mathrm{~mm} \mathrm{~K}^{-1}$. The negative slopes imply that the decreases in runoff are due to high temperatures and low precipitation. The positive slopes are mainly distributed over the Tibetan Plateau, Sichuan Basin, and northern coastal areas, where the rising temperature in the summer favors convection that leads to precipitation and then increases in runoff. Alternatively, temperatures and precipitation decreased in the Sichuan Basin in 1961-2008 (Lu et al. 2014). These findings highlight the differentiation of the response of runoff to climatic covariates with variable magnitudes of variation.

\section{Summary}

This study aimed to investigate the long-term variability of runoff and its links to climate variables (precipitation and temperature herein) over China using land processes modeling, observational datasets, and the quantile regression method. Compared with in situ measurements of soil moisture, streamflow, and GRACE terrestrial water storage, the evaluation demonstrated that CLM 3.5 could simulate the regional land water cycle reasonably well. Accordingly, the long-term runoff variability and its links to local climate were investigated using quantile regression.

Over China, the climatological runoff distribution is characterized by maxima in the humid southeast and minima in the arid northwest. There is a strong increasing trend in the humid regions $\left(0.35 \mathrm{~mm} \mathrm{mo}^{-1}\right.$ on average) but a decreasing trend in the transition zone $\left(-0.19 \mathrm{~mm} \mathrm{mo}{ }^{-1}\right)$, with nonsignificant trends in the arid northwest. The quantile slopes consistently decreased or increased in the critical regions, with the fastest increase over the positive trends region and the slowest decrease in the negative trends region, both at the 0.9 quantile.

Precipitation is critical to the summer runoff variations. The maximum correlation is seen in the humid regions for both summer and annual time means. Decreased positive correlation is consistently seen in the wet-dry transition zone. Over the arid regions, however, the correlation for the summer and annual means shows the opposite sign. The sensitivity of the runoff to climatic covariates is spatially stable but with significant degree changes. The response between runoff and temperature shows that the effect of increasing temperature on runoff is complex at the various spatiotemporal scales. With increasing temperature, the lower quantile of runoff decreased, whereas the upper quantile increased in the sorted summer runoff series. Spatially, the most sensitive coupling covers the region south of the Yangtze River. 
The aforementioned findings regarding the spatiotemporal variability of runoff over China will improve our understanding of the historical variability of runoff and its links to climate change and water resources countrywide. Nevertheless, the interpretation of the interactions between runoff and temperature requires more observations and model improvements in the future.

Acknowledgments We sincerely thank three anonymous reviewers for constructive comments and suggestions. This work was supported by the National Basic Research Program of China (2012CB956202), the China Special Fund for Meteorological Research in the Public Interest (GYHY201506001), and the National Natural Science Foundation of China project (41575087).

Open Access This article is distributed under the terms of the Creative Commons Attribution 4.0 International License (http://creativecommons.org/licenses/by/4.0/), which permits unrestricted use, distribution, and reproduction in any medium, provided you give appropriate credit to the original author(s) and the source, provide a link to the Creative Commons license, and indicate if changes were made.

\section{References}

Asadieh B, Krakauer NY (2015) Global trends in extreme precipitation: climate models versus observations. Hydrol Earth Syst Sc 19(2):877-891. doi:10.5194/hess-19-877-2015

Bi H, Liu B, Wu J, Yun L, Chen Z, Cui Z (2009) Effects of precipitation and landuse on runoff during the past 50 years in a typical watershed in the loess plateau. China International Journal of Sediment Research 24(3): 352-364

Branstetter ML, Erickson DJ (2003) Continental runoff dynamics in the community climate system model 2 (CCSM2) control simulation. J Geophys Res-Atmos 108(D17). doi:10.1029/2002jd003212

Chen YN, Takeuchi K, Xu CC, Chen YP, Xu ZX (2006) Regional climate change and its effects on river runoff in the Tarim Basin. China Hydrological Processes 20(10):2207-2216. doi:10.1002/hyp.6200

Chen J, Wu XD, Finlayson BL, Webber M, Wei TY, Li MT, Chen ZY (2014) Variability and trend in the hydrology of the Yangtze river, China: annual precipitation and runoff. J Hydrol 513:403-412. doi:10.1016/ j.jhydrol.2014.03.044

Dai A, Qian T, Trenberth KE, Milliman JD (2009) Changes in continental freshwater discharge from 1948 to 2004. J Clim 22(10):2773-2792. doi:10.1175/2008jcli2592.1

Ding YH, Wang ZY, Sun Y (2008) Inter-decadal variation of the summer precipitation in east China and its association with decreasing Asian summer monsoon. Part I: observed evidences. Int J Climatol 28(9):11391161. doi: $10.1002 /$ joc. 1615

IPCC (2013) Climate change 2013: the physical science basis. Contribution of working group I to the fifth assessment report of the intergovernmental panel on climate change. Cambridge University Press, Cambridge, United Kingdom and New York, NY, USA. doi:10.1017/CBO9781107415324

Landerer FW, Swenson SC (2012) Accuracy of Scaled GRACE Terrestrial Water Storage Estimates Water Resources Research:48. doi:10.1029/2011wr011453

Lawrence PJ, Chase TN (2007) Representing a new MODIS consistent land surface in the Community Land Model (CLM 3.0). J Geophys Res Biogeosci 112(G1). doi:G01023 Artn g01023

Lawrence D, Oleson KW, Flanner MG, Thorton PE, Swenson SC, Lawrence PJ, Zeng X, Yang Z-L, Levis S, Skaguchi K, Bonan GB, Slater AG (2011) Parameterization improvements and functional and structural advances in version 4 of the Community Land Model. J Adv Model Earth Syst 3(M03001):27. doi:10.1029/ 2011/ms000045

Li MX, Ma ZG (2010) Comparisons of simulations of soil moisture variations in the yellow river basin driven by various atmospheric forcing data sets. Adv Atmos Sci 27(6):1289-1302. doi:10.1007/ s00376-010-9155-7

Li MX, Ma ZG (2015) Soil moisture drought detection and multi-temporal variability across China. Science China Earth Sciences 58(10):1798-1813

Li MX, Ma ZG, Niu GY (2011) Modeling spatial and temporal variations in soil moisture in China. Chin Sci Bull 56(17):1809-1820. doi:10.1007/s11434-011-4493-0

Lu E, Zeng YT, Luo YL, Ding Y, Zhao W, Liu SY, Gong LQ, Jiang Y, Jiang ZH, Chen HS (2014) Changes of summer precipitation in China: the dominance of frequency and intensity and linkage with changes in moisture and air temperature. J Geophys Res-Atmos 119(22):12575-12587. doi:10.1002/2014jd022456 
McCabe GJ, Wolock DM (2011) Independent Effects of Temperature and Precipitation on Modeled Runoff in the Conterminous United States Water Resources Research:47. doi:10.1029/2011wr010630

Niu GY, Yang ZL, Dickinson RE, Gulden LE (2005) A simple TOPMODEL-based runoff parameterization (SIMTOP) for use in global climate models. J Geophys Res Atmos 110(D21106). doi:10.1029/ 2005jd006111

Niu GY, Yang ZL, Mitchell KE, Chen F, Ek MB, Barlage M, Kumar A, Manning K, Niyogi D, Rosero E, Tewari M, Xia YL (2011) The community Noah land surface model with multiparameterization options (NoahMP): 1. Model description and evaluation with local-scale measurements. J Geophys Res Atmos 116(D12109). doi:10.1029/2010jd015139

Oki T, Kanae S (2006) Global hydrological cycles and world water resources. Science 313(5790):1068-1072. doi: $10.1126 /$ science. 1128845

Oleson KW, Dai YJ, Bonan G, Bosilobich M, Dirmeyer P (2004) Technical description of the Community Land Model (CLM), NCAR Tech. Note NCAR/TN-461 + STR, Natl. Cent. for Atmos. Res., Boulder, Colo.: $173 \mathrm{pp}$

Oleson KW, Niu GY, Yang ZL, Lawrence DM, Thornton PE, Lawrence PJ, Stockli R, Dickinson RE, Bonan GB, Levis S, Dai A, Qian T (2008) Improvements to the community land model and their impact on the hydrological cycle. Journal of Geophysical Research-Biogeosciences 113(G1). doi:10.1029/2007JG000563

Sheffield J, Goteti G, Wood EF (2006) Development of a 50-yr high-resolution global dataset of meteorological forcings for land surface modeling. J Clim 19(13):3088-3111

Wentz FJ, Ricciardulli L, Hilburn K, Mears C (2007) How much more rain will global warming bring? Science 317(5835):233-235. doi:10.1126/science.1140746

Wu P, Wood R, Ridley J, Lowe J (2010) Temporary acceleration of the hydrological cycle in response to a CO2 rampdown. Geophys Res Lett 37. doi:10.1029/2010g1043730

Wu P, Christidis N, Stott P (2013) Anthropogenic impact on earth's hydrological cycle. Nat Clim Chang 3(9): 807-810. doi:10.1038/nclimate1932

$\mathrm{Xu}$ JX (2015) Complex response of runoff-precipitation ratio to the rising air temperature: the source area of the yellow river. China Regional Environmental Change 15(1):35-43. doi:10.1007/s10113-014-0617-9

Xue YK, Sun SF, Lau KM, Ji JJ, Poccard I, Zhang RH, Kang HS, Wu GX, Schaake JC, Zhang JY, Jiao YJ (2005) Multiscale variability of the river runoff system in China and its long-term link to precipitation and sea surface temperature. J Hydrometeorol 6(4):550-570. doi:10.1175/jhm439.1

Yang ZL, Niu GY (2003) The versatile integrator of surface and atmosphere processes - part 1. Model description. Glob Planet Chang 38:175-189. doi:10.1016/s0921-8181(03)00028-6

Zhai PM, Zhang XB, Wan H, Pan XH (2005) Trends in total precipitation and frequency of daily precipitation extremes over China. J Clim 18(7):1096-1108. doi:10.1175/jcli-3318.1

Zhang Q, Xu C-y, Becker S, Jiang T (2006) Sediment and runoff changes in the Yangtze river basin during past 50 years. J Hydrol 331:511-523. doi:10.1016/j.jhydrol.2006.05.036

Zhang Q, Xu C-Y, Yang T (2009) Variability of water resource in the yellow river basin of past 50 years. China Water Resources Management 23(6):1157-1170. doi:10.1007/s11269-008-9320-2

Zhang AJ, Zhang C, Fu GB, Wang BD, Bao ZX, Zheng HX (2012) Assessments of impacts of climate change and human activities on runoff with SWAT for the huifa river basin, northeast China. Water Resour Manag 26(8):2199-2217. doi:10.1007/s11269-012-0010-8

Zhang Q, Xiao MZ, Singh VP, Xu CY, Li JF (2015) Variations of annual and seasonal runoff in Guangdong province, south China: spatiotemporal patterns and possible causes. Meteorog Atmos Phys 127(3):273-288. doi:10.1007/s00703-014-0360-2 